\title{
Vitamin D and Nonskeletal Complications among Egyptian Sickle Cell Disease Patients
}

\author{
Mona Hamdy, ${ }^{1}$ Niveen Salama $\mathbb{D},{ }^{1}$ Ghada Maher, ${ }^{2}$ and Amira Elrefaee ${ }^{1}$ \\ ${ }^{1}$ Department of Pediatrics, Faculty of Medicine, Cairo University, Cairo, Egypt \\ ${ }^{2}$ Department of Chemical Pathology, Faculty of Medicine, Cairo University, Cairo, Egypt
}

Correspondence should be addressed to Niveen Salama; niveensab@yahoo.com

Received 16 May 2018; Accepted 15 August 2018; Published 16 September 2018

Academic Editor: Estella M. Matutes

Copyright (c) 2018 Mona Hamdy et al. This is an open access article distributed under the Creative Commons Attribution License, which permits unrestricted use, distribution, and reproduction in any medium, provided the original work is properly cited.

Lower levels of vitamin D have been documented in many patients with sickle cell disease (SCD), but data are still inconclusive regarding the association between vitamin D deficiency (VDD) and the occurrence or the severity of various SCD complications. Our study aimed to detect the prevalence of vitamin D deficiency among Egyptian patients with SCD and to associate it with the clinical course of the disease. We measured the level of 25-hydroxy vitamin D in 140 children (age from 4.3 to 15.5 years), 80 patients with SCD and 60 controls using enzyme-linked immunosorbent assay. Vitamin D was deficient in $60 \%$ of SCD compared to $26.7 \%$ of controls. Severe VDD was significantly higher in SCD patients than controls. Patients were divided into 2 groups; Normal group (32 patients) and Deficient group (48 patients). There were statistically significant differences between the 2 groups regarding their age, height percentile, the presence of clinical jaundice, and osseous changes ( $\mathrm{P}$ values $0.043,0.024,0.001$, and 0.015 , respectively). Hemoglobin and hematocrit values were significantly lower in Deficient group (P values 0.022 and 0.004 , respectively) while the levels of aspartate aminotransferase, lactate dehydrogenase, and total and indirect bilirubin were significantly higher in the same group (P values $0.006,0.001,0.038$, and 0.016 , respectively). The frequency of blood transfusions, hospitalization, and vasoocclusive crisis previous year as well as the history of bone fracture and recurrent infections proved to be significantly higher in Deficient group. These findings suggest that VDD may play a role in the pathogenesis of hemolysis and other complication of SCD. Vitamin D monitoring and supplementation in patients with SCD should be implemented as a standard of care to potentially improve health outcomes in these affected patients.

\section{Introduction}

Vitamin D has been the focus of attention of many researchers concerned with general health as well as specific diseases. Though exposure of the skin to the ultraviolet (UV) sun rays is the main source of de novo vitamin D synthesis [1], North African and Middle Eastern countries, with abundant sun all over the year, reported the highest frequencies of vitamin D deficiency (VDD) in all age groups world-wide $[2,3]$.

Studies in patients with sickle cell disease (SCD) revealed high prevalence of VDD in these patients regardless of their age or ethnic background [4-7]. Predisposing factors that can contribute to such deficiency include decreased synthesis of vitamin $\mathrm{D}$ from sunlight due to skin pigmentation and limited outdoor activity, diminished exogenous supply as a result of poor appetite and impaired absorption by the damaged intestinal mucosa as a complication of SCD, and increased metabolic requirements due to increased erythrocyte production to compensate for shortened lifespan of the red cells and also decreased level of vitamin D binding protein 'which is known in inflammatory conditions as SCD' resulting in decreased serum level of vitamin D. Finally impaired renal function which is known in many patients with SCD interferes with hydroxylation of vitamin D to 25hydroxy-vitamin D (25-OHD) [4, 8].

Vitamin D deficiency has been linked to many skeletal and extraskeletal disorders including cardiovascular diseases [9], respiratory disorders, and asthma [10]. Vitamin D also has immunomodulatory and antimicrobial activities that affect both innate and acquired immunity [11]; all these disorders could have direct impact on the clinical course of SCD. In addition, suboptimal vitamin $\mathrm{D}$ levels have been detected 
in many pathological conditions associated with SCD such as vasoocclusive crises (VOC) [8], chronic pain [12], bone fragility [13], renal impairment [14], and autoimmune and inflammatory disorders [15]. Whether VDD initiates or exacerbates these disorders and the effect of its supplementation on their clinical courses remains to be determined.

Few studies are available regarding the nutritional status of SCD patients, including their vitamin D levels, and even fewer correlate specific nutritional deficiencies to the clinical profile of these patients.

Aim of Work. Our study was conducted to determine vitamin D status in Egyptian children and adolescents with sickle cell disease and to detect the effect of its deficiency on the clinical course of the disease as regards VOC, hemolysis, and other complications of the disease.

\section{Materials and Methods}

This is a case control cross-sectional study conducted on the Hematology Clinic, New Children Hospital, Cairo University. Eighty SCD patients and 60 age and sex frequency matched healthy control were enrolled. Informed consent was obtained from all patients, controls, and/or their legal guardians. Our study was conducted in accordance with the Declaration of Helsinki and was approved by the ethical committee of the New Children Hospital, Cairo University. All cases were in steady state indicated by the absence of any painful episodes in last 4 weeks prior to enrollment [17]. Patients older than 20 years and those with renal impairment, chronic malabsorption, osteoporosis, osteopenia, intercurrent infection or inflammation, and ongoing steroid therapy were excluded from the study. Clinical data were obtained from the patients' interviewing and medical records including anthropometric measures, number of blood transfusions, VOC, and hospital admissions in the last year.

VOC were classified as mild, moderate, and severe where mild and moderate VOC were managed at home (with non-steroidal anti-inflammatory drugs and weak opioid, respectively) while severe VOC required hospitalization and the use of strong opioid [18].

The cross-sectional nature of the study and the limited financial resources due to self-funding of the study hinder our ability to monitor vitamin $\mathrm{D}$ level all over the year, so blood sampling was performed during the summer months 'from June to August', taking into consideration the seasonal variation of vitamin D level with expected higher level of the vitamin during summer, assuming that deficient patients during summer are deficient in the other seasons.

Blood was withdrawn from all study populations in the outpatient clinic. Laboratory investigations included complete blood count, reticulocyte count, aspartate transaminase (AST), alanine transaminase (ALT), lactate dehydrogenase $(\mathrm{LDH})$, and total and indirect serum bilirubin.

2.1. 25-Hyroxyvitamin D. 25-OHD was measured for case and control groups as it is the major circulating form of
TABLE 1: The ranges for the classification of 25-hydrxyvitamin D status [16].

\begin{tabular}{lc}
\hline Vitamin D status & 25-OH Vitamin D (ng/ml) \\
\hline Severe deficiency & $<10$ \\
\hline Deficiency & $10-20$ \\
\hline Sufficiency & $20-30$. \\
\hline Toxicity & $>100$ \\
\hline
\end{tabular}

vitamin $\mathrm{D}$ and is considered the most accurate marker for vitamin D status [19].

2.2. Sample Collection, Storage, and Preparation. Blood samples were collected by venipuncture, allowed to clot, and then centrifuged at room temperature for 1 hour. Specimens were stored at 8 Celsius degrees for 3 days and or -20 Celsius longer duration.

2.3. Assay Procedures. Enzyme-linked immunosorbent assay (ELISA) was based on competitive binding using the DRYHYBRID-XL 25-OH Vitamin D kits. The walls of the reagents cartridge are coated with vitamin D binding protein (VDBP). Endogenous 25-OHD of the samples competes with a 25OHD-biotin for binding to the coated VDBP. After incubation the unbound conjugate is washed off, thereafter, bound 25-OHD-biotin conjugate is detected by streptavidinconjugated peroxidase (Enzyme complex). The amount of bound peroxidase conjugate is inversely proportional to the concentration of 25-OHD in the sample [20].

2.4. Expected Normal Values. Each laboratory should determine its own normal and pathological values. Our laboratory suggests the ranges in Table 1 for the classification of 25-OHD status [16].

The dynamic range of the assay is defined by the limit of detection and the maximum values of the Master curves. Values found below the measuring range are indicated as $<4.6 \mathrm{ng} / \mathrm{mL}$ and values above the measuring ranges are indicated as $>130 \mathrm{ng} / \mathrm{ml}$.

2.5. Statistical Analysis. The data were analyzed using the Splus Statistics Software (SPSS version 21). Descriptive statistical calculations (mean \pm standard deviation) were done to quantitative values. Statistical analyses were performed using the independent $t$-test as applicable for quantitative variables. Fisher exact test and Pearson Chi-Square test were used for qualitative variables. Two-tailed P-values of less than 0.05 were considered to be significant. The Pearson correlation coefficient ( $\mathrm{r}$ ) was used to express the relationship between quantitative variables in different groups.

\section{Results}

The study populations were composed of 80 Egyptian cases with SCD, compared to 60 age and sex frequency matched healthy controls with male-to-female ratios 1.4: 1 and 1.3:1, respectively. Case group consisted of 59 (73.8\%) patients with 
TABle 2: Demographic and laboratory data of the case and control groups.

\begin{tabular}{|c|c|c|c|}
\hline Variable & $\operatorname{Case}(n=80)$ & Control $(n=60)$ & $P$-value \\
\hline Age: in years:median (IQR) & $9(7.5)$ & $9.5(8)$ & 0.753 \\
\hline Sex: n (\%) & & & 0.522 \\
\hline Male (\%) & $47(58.8 \%)$ & $34(56.6 \%)$ & \\
\hline Female (\%) & $33(41.2 \%)$ & $26(43.3 \%)$ & \\
\hline Hemoglobin (g/dl): mean \pm SD & $8.3 \pm 1.4$ & $13.2 \pm 1.8$ & Less than 0.001 \\
\hline Hematocrit (\%): mean \pm SD & $25.5 \pm 4.8$ & $37 \pm 3.9$ & Less than 0.001 \\
\hline MCV (FL): mean \pm SD: & $84.5 \pm 8.8$ & $88.1 \pm 6.8$ & 0.008 \\
\hline $\mathrm{MCH}(\mathrm{pg}):$ mean $\pm \mathrm{SD}$ & $25.0 \pm 3$ & $32.3 \pm 1.7$ & Less than 0.001 \\
\hline WBC $\left(10^{3} \mathrm{~mm}^{2}\right):$ mean \pm SD & $9.2 \pm 4.4$ & $7.9 \pm 2.1$ & 0.033 \\
\hline Platelets $\left(10^{3} \mathrm{~mm}^{2}\right)$ : mean \pm SD & $328.2 \pm 164.4$ & $284.7 \pm 106.4$ & 0.067 \\
\hline 25-OHD (ng/ml): mean \pm SD & $22 \pm 10.4$ & $22.7 \pm 8.4$ & 0.658 \\
\hline No Deficiency: n (\%) & $32(40 \%)$ & $44(73.3 \%)$ & 0.061 \\
\hline Deficiency: n (\%) & $48(60 \%)$ & $16(26.7 \%)$ & 0.058 \\
\hline Severe deficiency: $\mathrm{n}(\%)$ & $13(16.2 \%)$ & $5(8.3 \%)$ & 0.021 \\
\hline $25-\mathrm{OHD}$ in VDD groups $(\mathrm{ng} / \mathrm{ml}):$ mean $\pm \mathrm{SD}$ & $9.9 \pm 2.1$ & $11 \pm 1.8$ & 0.049 \\
\hline
\end{tabular}

$\mathrm{n}=$ number. $\mathrm{IQR}=$ interquartile range. $\mathrm{SD}=$ standard deviation. $25-\mathrm{OHD}=25$-hydroxyvitamin $\mathrm{D} . \mathrm{MCV}=$ mean corpuscular volume. $\mathrm{MCH}=$ mean corpuscular hemoglobin. $\mathrm{WBC}=$ white blood cells. $\mathrm{VDD}=$ vitamin $\mathrm{D}$ deficiency. Bold values indicate statistical significance.

homozygous hemoglobin S (HBSS) and 21(26.2\%) patients with sickle $\beta$-thalassemia $(H B S \beta)$. The demographic and laboratory data of the 2 groups are shown in Table 2 .

There were statistically significant differences between case and control groups regarding the level of hemoglobin $(\mathrm{Hb})$, hematocrit, mean corpuscular volume (MCV), mean corpuscular hemoglobin $(\mathrm{MCH})$, and white blood cell (WBC) counts.

Cases of sickle cell disease were divided into 2 groups: 'Normal group' with normal vitamin D level (32 patients) and 'Deficient group' with VDD (48 patients). Table 3 showed the demographic and laboratory data of the 2 groups.

There were statistically significant differences between the 2 groups regarding their age, height percentile, and the presence of clinical jaundice and osseous changes ( $P$ values $0.043,0.024,0.001$ and 0.015 , respectively). Regarding lab results, hemoglobin and hematocrit values were significantly lower in Deficient group (P values 0.022 and 0.004, respectively) while the levels of aspartate aminotransferase, lactate dehydrogenase, and total and indirect bilirubin were significantly higher in the same group ( $\mathrm{P}$ values $0.006,0.001$, 0.038 , and 0.016 , respectively).

Data from Table 4 shows weak but statistically significant correlation between serum 25-OHD and the biomarker of hemolysis and red blood cell turnover. VDD patients had lower level of hemoglobin and hematocrit and higher level of AST, LDH, and total and indirect bilirubin.

The association between VDD and the clinical course and complications of SCD is shown in Table 5.

The frequencies of blood transfusions and hospitalization last year were significantly higher in Deficient group; also the occurrence of vasoocclusive crises last year and the presence of old fractured bone and recurrent infections proved to be statistically significant.

\section{Discussion}

The reported incidences of VDD range from 20 to $80 \%$ in some Middle Eastern counties [21]. Despite these high incidences, VDD often remained underdiagnosed and untreated especially in patients with SCD where chronic pain of VDD was usually credited to SCD, as the pain in both conditions is dull aching and deeply seated and involves the back and extremities [22].

In our study, we found $26.7 \%$ incidence of VDD among the healthy control group; however, further population based studies are needed to evaluate vitamin D status among the Egyptians. Forty-eight (60\%) of our SCD patients and 16 (26.7\%) of controls were found to have VDD, with 13 cases and 5 controls having severe deficiency with statistically significant difference between the two groups. These results are in close approximation to those obtained from Spain [23] and Turkey [24] where the prevalence of VDD among SCD patients was $56.4 \%$ and $63.1 \%$, respectively, while the prevalence of severe VDD $(25-\mathrm{OH}$ D level $<10 \mathrm{ng} / \mathrm{ml}$ ) was $12 \%$ in a study on sickle patients conducted in Saudi Arabia [25].

We detected a weak negative correlation between age and vitamin D level; the older the age, the lower the level. This correlation 'which is well established by other studies $[1,26]$ ' could be weak due to the proximity in age distribution between our studied patients with VDD and those with normal vitamin $\mathrm{D}$ level. In older age patients, this negative correlation could be explained by prolonged course of the disease with more skin pigmentation, more intestinal mucosal damage, and renal impairment which all affect vitamin D metabolism.

We did not detect any significant correlation between sickle disease genotype and vitamin D status. This finding 
TABLE 3: Demographic and laboratory data of the 2 groups.

\begin{tabular}{|c|c|c|c|}
\hline Variable & Normal Group $(n=32)$ & Deficient Group $(n=48)$ & $P$-value \\
\hline Age: in years:median (IQR) & $8(9.235)$ & $11(5)$ & 0.043 \\
\hline Sex: n (\%) & & & 0.732 \\
\hline Male (\%) & $17(53.1 \%)$ & $30(62.5 \%)$ & \\
\hline Female (\%) & $15(46.9 \%)$ & $18(37.5 \%)$ & \\
\hline Weight percentile: mean \pm SD & $29.7 \pm 20.2$ & $22.1 \pm 18.2$ & 0.072 \\
\hline Height percentile: mean \pm SD & $33.8 \pm 26.5$ & $22.2 \pm 24.8$ & 0.024 \\
\hline Hemoglobin genotype: n (\%) & & & 0.635 \\
\hline HBSS (\%) & $26(81.3 \%)$ & $33(68.7 \%)$ & \\
\hline$H B S B+(\%)$ & $5(15.6 \%)$ & $11(20.8 \%)$ & \\
\hline HBSBO (\%) & $1(3.1 \%)$ & $4(10.5 \%)$ & \\
\hline Splenomegaly: $\mathrm{n}(\%)(\mathrm{n}=28)$ & $12(37.5)$ & $16(33.4)$ & 0.655 \\
\hline Splenectomy: n (\%) $(\mathrm{n}=22)$ & $7(31.8)$ & $15(68.2)$ & 0.156 \\
\hline Pallor: $\mathrm{n}(\%)(\mathrm{n}=38)$ & $12(31.5)$ & $26(68.5)$ & 0.267 \\
\hline Jaundice: $\mathrm{n}(\%)(\mathrm{n}=21)$ & $1(4.8)$ & $20(95.2)$ & 0.001 \\
\hline Osseous changes: $\mathrm{n}(\%)(\mathrm{n}=13)$ & $3(23)$ & $10(76)$ & 0.015 \\
\hline Hemoglobin (g/dL): mean \pm SD & $8.6 \pm 1.1$ & $7.9 \pm 1.6$ & 0.022 \\
\hline Hematocrit (\%): mean \pm SD & $26.9 \pm 4$ & $23.9 \pm 5.1$ & 0.004 \\
\hline Reticulocyte count (\%): mean \pm SD & $4.8 \pm 2.9$ & $6.5 \pm 4.1$ & 0.063 \\
\hline Corrected Reticulocyte count (\%): mean \pm SD & $2.6 \pm 1.4$ & $3 \pm 2.1$ & 0.401 \\
\hline AST (IU/L): mean \pm SD & $43.3 \pm 23.3$ & $54.4 \pm 20.1$ & 0.006 \\
\hline ALT (IU/L): mean \pm SD & $25.1 \pm 20.3$ & $27.1 \pm 18.8$ & 0.540 \\
\hline LDH (IU/L): mean \pm SD & $454.8 \pm 279.4$ & $634.9 \pm 277.8$ & 0.001 \\
\hline TSB (mg/dL): mean \pm SD & $4.2 \pm 2.4$ & $5.9 \pm 3.5$ & $\mathbf{0 . 0 3 8}$ \\
\hline Indirect bilirubin $(\mathrm{mg} / \mathrm{dL})$ : mean $\pm \mathrm{SD}$ & $2 \pm 1.8$ & $2.6 \pm 1.4$ & 0.016 \\
\hline
\end{tabular}

TABLE 4: Correlation between Serum 25-OHD and biomarkers of intravascular femolysis.

\begin{tabular}{lcc}
\hline Variable & Correlation Coefficient(r) & P.value \\
\hline Hemoglobin (g/dl) & 0.27 & $\mathbf{0 . 0 1 9}$ \\
Hematocrit (\%) & 0.29 & $\mathbf{0 . 0 1 1}$ \\
Reticulocyte count (\%) & -0.31 & $\mathbf{0 . 0 0 7}$ \\
Corrected Reticulocyte count (\%) & 0.061 \\
AST & -0.22 & $\mathbf{0 . 0 0 3}$ \\
ALT & -0.33 & 0.618 \\
LDH & -0.05 & $\mathbf{0 . 0 1 7}$ \\
TSB & -0.27 & $\mathbf{0 . 0 1 0}$ \\
Indirect SB & -0.29 & $\mathbf{0 . 0 0 2}$ \\
\hline
\end{tabular}

$\mathrm{AST}=$ aspartate transaminase; $\mathrm{ALT}=$ alanine transaminase; $\mathrm{LDH}=$ lactate dehydrogenase; $\mathrm{TSB}=$ total serum bilirubin; indirect $\mathrm{SB}=$ indirect serum bilirubin . Bold values indicate statistical significance.

was supported by similar study performed on SCD patients in Spanish population [23].

In our study, we found significantly lower height percentile in SCD patient with VDD than those with normal vitamin D level, while the weight percentile was lower though did not reach significance. Other studies [24, 25] showed impairment in both weight and height percentile among SCD patients with VDD compared to those with sufficient vitamin D. Further verification studies are needed to detect the impacts of VDD on the patients' growth parameters.

A statistically significant correlation was observed between vitamin D level and biomarkers of hemolysis. Lower vitamin D levels were associated with lower hemoglobin and hematocrit but with higher reticulocyte counts, AST, $\mathrm{LDH}$, and total and indirect serum bilirubin levels. Whether VDD increases hemolysis or excessive hemolysis increases 
TABLE 5: Association between VDD, clinical course, and complications of SCD.

\begin{tabular}{|c|c|c|c|}
\hline Variable & Normal Group $(n=32)$ & Deficient Group $(n=48)$ & $P$-value \\
\hline Blood transfusion: $\mathrm{n}(\%)(\mathrm{n}=69)$ & $30(43.4)$ & $39(56.6)$ & 0.475 \\
\hline Age at $1^{\text {st }}$ blood transfusion (years) & $2.3 \pm 1.9$ & $1.6 \pm 1.0$ & 0.351 \\
\hline Frequency of blood transfusion/ Last year & $3.6 \pm 2.8$ & $5.4 \pm 3.5$ & 0.021 \\
\hline Positive VOC/ Last year: $\mathrm{n}(\%)(\mathrm{n}=68)$ & $24(35.2)$ & $44(64.8)$ & 0.032 \\
\hline Degree of VOC: $\mathrm{n}(\%)$ & & & 0.732 \\
\hline Mild $(\mathrm{n}=41)$ & $13(31.7)$ & $28(68.3)$ & \\
\hline Moderate $(n=21)$ & $10(47.6)$ & $11(52.4)$ & \\
\hline Severe $(n=6)$ & $1(16.6)$ & $5(83.4)$ & \\
\hline Hospital admission/ Last year: $\mathrm{n}(\%)(\mathrm{n}=44)$ & $14(31.8)$ & $30(68.2)$ & 0.012 \\
\hline Bone fracture: $\mathrm{n}(\%)(\mathrm{n}=8)$ & $1(12.5)$ & $7(87.5)$ & 0.034 \\
\hline Recurrent infection: $\mathrm{n}(\%)(\mathrm{n}=36)$ & $7(19.5)$ & $29(80.5)$ & 0.036 \\
\hline Viral hepatitis (B\&C): $\mathrm{n}(\%)(\mathrm{n}=12)$ & $5(41.6)$ & $7(58.4)$ & 0.219 \\
\hline Pulmonary hypertension: $\mathrm{n}(\%)(\mathrm{n}=11)$ & $3(27.3)$ & $8(72.7)$ & 0.068 \\
\hline Diabetes Mellitus: $\mathrm{n}(\%)(\mathrm{n}=4)$ & $2(50)$ & $2(50)$ & 0.721 \\
\hline Abnormal TCD: $\mathrm{n}(\%)(\mathrm{n}=2)$ & $1(50)$ & $1(50)$ & 0.834 \\
\hline Gall Bladder stones: $\mathrm{n}(\%)(\mathrm{n}=3)$ & $1(33.3)$ & $2(66.7)$ & 0.059 \\
\hline
\end{tabular}

$\mathrm{n}=$ number; $\mathrm{SD}=$ standard deviation; $\mathrm{VOC}=$ vasoocclusive crisis; $\mathrm{TCD}=$ transcranial Doppler. Bold values indicate statistical significance.

the demand of vitamin $\mathrm{D}$ is still debatable. Winters and colleagues suggested that increased hemolysis and bone marrow activity may interfere with vitamin $\mathrm{D}$ absorption leading to VDD [26], while other authors suggested that VDD may increase hemolysis of RBCs in patient with SCD [19].

Low "hemoglobin and hematocrit" and high "reticulocyte count and LDH" were associated with significantly lower level of vitamin D in other studies [27-29]. A recent study showed a positive correlation between hemoglobin concentration and vitamin $\mathrm{D}$ level where $1 \mathrm{~g} / \mathrm{L}$ hemoglobin increase was associated with $0.4 \mathrm{nmol} / \mathrm{L}$ increase of serum vitamin $\mathrm{D}$ level [30]; however, others showed nonsignificant correlation between vitamin $\mathrm{D}$ level and hemoglobin, hematocrit, reticulocyte count, or AST level $[5,19,31]$.

We have noticed that, throughout the year prior to enrollment, SCD patients with VDD had significantly higher incidences of VOC, blood transfusions, hospital or emergency room visits, and recurrent infections as compared to those with normal vitamin D level.

Vasoocclusive crisis is the hallmark of SCD and the main cause of healthcare utilization. Our study along with other studies $[8,32]$ provided evidence that painful episodes in SCD correlate positively with VDD, the mechanism of which is still unclear, but a recent study associates lower vitamin $\mathrm{D}$ level to increased expression of SLC6A5 gene which encodes for a neuronal pain pathway protein called glycine tranporter2 which may have a direct effect on the nervous system. Impaired bone health may also contribute to these painful episodes [32, 33]; Osunkwo and colleagues also proved that proper vitamin $\mathrm{D}$ therapy could reduce the number of painful days and improve quality of life [12]. Though others failed to detect any association between VDD and the number of painful episode, this could be explained by the high incidence (96.4\%) of VDD among the studied sample [34].
The role of vitamin $\mathrm{D}$ in both innate and acquired immunity has been well established; vitamin $\mathrm{D}$ activated at extrarenal sites supports innate immunity by stimulating the expression of Cathelicidin, "member of a group of antimicrobial peptide called Defensins", which is usually suppressed by pathogens [11]. Vitamin D also exhibits a pivotal role in both cell mediated and humoral immune responses by modulating the proliferation of $\mathrm{T}$ lymphocytes and regulating cytokines production and also through downregulation of B lymphocyte proliferation, antibodies production, and cell switching to plasma or memory cell $[35,36]$. In our study, we detected a significantly higher incidence of respiratory and urinary tract infections among patients with VDD. Several studies conducted in children confirmed our findings of significant association between VDD and increased risk of viral and bacterial respiratory tract infections [37-39]; Urashima and colleagues even suggest that vitamin D supplementation plays a role in prevention of seasonal influenza [40]. Other authors encounter more than 50\% reduction of the respiratory illness rate on the second year of monthly vitamin D supplementation [41].

Our study has its own limitations: first, the studied sample being collected from patient attending SCD clinic at a single tertiary care hospital which may not represent all patients with SCD; second, the lack of community-based studies to detect the prevalence of VDD among the Egyptian population; lastly, the lack of proper dietary and medication history including vitamins supplementation.

\section{Conclusions and Recommendations}

Vitamin D deficiency is a major nutritional health problem in patients with sickle cell disease that may aggravate the disease process and increase the risk of its complications. Further prospective and interventional studies are needed to 
confirm the causal relationship between VDD and suspected complications and the effect and proper dose of vitamin D replacement before considering vitamin $\mathrm{D}$ as an adjunct therapy in SCD management; however, periodic measurement of vitamin $\mathrm{D}$ level should be implemented as primary care point in patients with SCD.

\section{Data Availability}

The data used to support the findings of this study are available from the corresponding author upon request.

\section{Disclosure}

The current address of Mona Hamdy, Niveen Salama and Amira Elrefaee is New Children Hospital, Abu El Rish, Cairo University Hospital, Cairo, Egypt. The current address of Ghada Maher is Kaser El Einy Hospital, Cairo University Hospital, Cairo, Egypt. This study is self-funded by the authors.

\section{Conflicts of Interest}

The authors declare that they have no conflicts of interest.

\section{Authors' Contributions}

Mona Hamdy and Niveen Salama contributed equally in this work being joint senior authors. Ghada Maher and Amira Elrefaee also contributed equally in this work being responsible for samples collection and analysis.

\section{Acknowledgments}

The authors would like to express their sincere gratitude and respect to all the staff at the Hematology Clinic of Cairo University Children's Hospital, for their continuous efforts, support, and patience. Without their help and guidance, this study could not be conducted. They would like also to thank all the patients with sickle cell disease for their great spirits, cooperation, and commitment in providing the required data and samples.

\section{References}

[1] C. Wykes, A. Arasaretnam, S. O'Driscoll, L. Farnham, C. Moniz, and D. C. Rees, "Vitamin D deficiency and its correction in children with sickle cell anaemia," Annals of Hematology, vol. 93, no. 12, pp. 2051-2056, 2014.

[2] C. Palacios and L. Gonzalez, "Is vitamin D deficiency a major global public health problem?" The Journal of Steroid Biochemistry and Molecular Biology, vol. 144, no. Part A, pp. 138-145, 2014.

[3] D. Bassil, M. Rahme, M. Hoteit, and G. E.-H. Fuleihan, "Hypovitaminosis D in the Middle East and North Africa Prevalence, risk factors and impact on outcomes," DermatoEndocrinology, vol. 5, no. 2, pp. 274-298, 2013.

[4] V. G. Nolan, K. A. Nottage, E. W. Cole, J. S. Hankins, and J. G. Gurney, "Prevalence of vitamin D deficiency in sickle cell disease: a systematic review," PLoS ONE, vol. 10, no. 3, Article ID e0119908, 2015.

[5] A. M. Buison, D. A. Kawchak, J. Schall, K. Ohene-Frempong, V. A. Stallings, and B. S. Zemel, "Low vitamin D status in children with sickle cell disease," Journal of Pediatrics, vol. 145, no. 5, pp. 622-627, 2004.

[6] P. C. Boettger, C. L. Knupp, D. K. Liles, and K. Walker, "Vitamin D Deficiency in Adult Sickle Cell Patients," Journal of the National Medical Association, vol. 109, no. 1, pp. 36-43, 2017.

[7] B. O. Tayo, T. S. Akingbola, B. L. Salako et al., "Vitamin D levels are low in adult patients with sickle cell disease in Jamaica and West Africa," BMC Hematology, vol. 14, no. 1, 2014.

[8] M. T. Lee, M. Licursi, and D. J. Mcmahon, "Vitamin D deficiency and acute vaso-occlusive complications in children with sickle cell disease," Pediatric Blood \& Cancer, vol. 62, no. 4, pp. 643-647, 2015.

[9] T. J. Wang, M. J. Pencina, S. L. Booth et al., "Vitamin D deficiency and risk of cardiovascular disease," Circulation, vol. 117, no. 4, pp. 503-511, 2008.

[10] A. Gupta, A. Sjoukes, D. Richards et al., "Relationship between serum vitamin $\mathrm{D}$, disease severity, and airway remodeling in children with asthma," American Journal of Respiratory and Critical Care Medicine, vol. 184, no. 12, pp. 1342-1349, 2011.

[11] J. S. Adams and M. Hewison, "Unexpected actions of vitamin D: new perspectives on the regulation of innate and adaptive immunity," Nature Clinical Practice: Endocrinology \& Metabolism, vol. 4, no. 2, pp. 80-90, 2008.

[12] I. Osunkwo, E. I. Hodgman, K. Cherry et al., "Vitamin D deficiency and chronic pain in sickle cell disease," British Journal of Haematology, vol. 153, no. 4, pp. 538-540, 2011.

[13] J.-B. Arlet, M. Courbebaisse, G. Chatellier et al., "Relationship between vitamin $\mathrm{D}$ deficiency and bone fragility in sickle cell disease: a cohort study of 56 adults," Bone, vol. 52, no. 1, pp. 206211, 2013.

[14] D. C. Rees and J. S. Gibson, "Biomarkers in sickle cell disease," British Journal of Haematology, vol. 156, no. 4, pp. 433-445, 2012.

[15] S. Unal, Y. Oztas, G. Eskandari, L. T. Gumus, and O. Nuriman, "The Association Between Vitamin D and Inflammation in Sickle Cell Disease," in Blood, vol. 124, 21 edition, 2014.

[16] M. F. Holick, N. C. Binkley, H. A. Bischoff-Ferrari et al., "Evaluation, treatment, and prevention of vitamin D deficiency: an endocrine society clinical practice guideline," The Journal of Clinical Endocrinology \& Metabolism, vol. 96, no. 7, pp. 19111930, 2011.

[17] S. K. Ballas, "More definitions in sickle cell disease: steady state v base line data," American Journal of Hematology, vol. 87, no. 3, p. 338, 2012.

[18] D. S. Darbari, Z. Wang, M. Kwak, M. Hildesheim, J. Nichols, and D. Allen, "Severe Painful Vaso-Occlusive Crises and Mortality in a Contemporary Adult Sickle Cell Anemia Cohort Study. PLoS One," in DOI, vol. 8, pp. e79923-10, e79923, 8(11, 2013.

[19] S. A. Adegoke, J. A. P. Braga, A. D. Adekile, and M. S. Figueiredo, "The Association of Serum 25-Hydroxyvitamin D with Biomarkers of Hemolysis in Pediatric Patients with Sickle Cell Disease," Journal of Pediatric Hematology/Oncology, vol. 40, no. 2, pp. 159-162, 2018.

[20] B. W. Hollis, "Editorial: The determination of circulating 25hydroxyvitamin D: No easy task," The Journal of Clinical Endocrinology \& Metabolism, vol. 89, no. 7, pp. 3149-3151, 2004.

[21] G. El-Hajj Fuleihan, "Vitamin D deficiency in the Middle East and its health consequences for children and adults," Clinical 
Reviews in Bone and Mineral Metabolism, vol. 7, no. 1, pp. 7793, 2009.

[22] A. AlJama, M. AlKhalifah, I. A. Al-Dabbous, and G. Alqudaihi, "Vitamin D deficiency in sickle cell disease patients in the Eastern Province of Saudi Arabia," Annals of Saudi Medicine, vol. 38, no. 2, pp. 130-136, 2018.

[23] C. Garrido, E. Cela, C. Beléndez, C. Mata, and J. Huerta, "Status of vitamin D in children with sickle cell disease living in Madrid, Spain," European Journal of Pediatrics, vol. 171, no. 12, pp. 17931798, 2012.

[24] S. Özen, S. Ünal, N. Erçetin, and B. Taşdelen, "Frequency and risk factors of endocrine complications in Turkish children and adolescents with sickle cell anemia," Turkish Journal of Hematology, vol. 30, no. 1, pp. 25-31, 2013.

[25] S. Mohammed, S. Addae, S. Suleiman et al., "Serum calcium, parathyroid hormone, and vitamin D status in children and young adults with sickle cell disease," Annals of Clinical Biochemistry, vol. 30, no. 1, pp. 45-51, 1993.

[26] A. C. Winters, W. Kethman, R. Kruse-Jarres, and J. Kanter, "Vitamin D insufficiency is a frequent finding in pediatric and adult patients with sickle cell disease and correlates with markers of cell turnover," Journal of Nutritional Disorders and Therapy, vol. 4, no. 140, 2014.

[27] A. Lal, E. B. Fung, Z. Pakbaz, E. Hackney-Stephens, and E. P. Vichinsky, "Bone mineral density in children with sickle cell anemia," Pediatric Blood \& Cancer, vol. 47, no. 7, pp. 901-906, 2006.

[28] T. S. Garadah, A. B. Hassan, A. A. Jaradat et al., "Predictors of abnormal bone mass density in adult patients with homozygous sickle-cell disease," Clinical Medicine Insights: Endocrinology and Diabetes, vol. 8, pp. 35-40, 2015.

[29] M. Sarrai, H. Duroseau, J. D'Augustine, S. Moktan, and R. Bellevue, "Bone mass density in adults with sickle cell disease," British Journal of Haematology, vol. 136, no. 4, pp. 666-672, 2007.

[30] K. Samson, H. McCartney, S. Vercauteren, J. Wu, and C. Karakochuk, "Prevalence of Vitamin D Deficiency Varies Widely by Season in Canadian Children and Adolescents with Sickle Cell Disease," Journal of Clinical Medicine, vol. 7, no. 2, p. $14,2018$.

[31] A. Ashraf, J. Alvarez, K. Saenz, B. Gower, K. McCormick, and F. Franklin, "Threshold for effects of vitamin D deficiency on glucose metabolism in obese female African-American adolescents," The Journal of Clinical Endocrinology \& Metabolism, vol. 94, no. 9, pp. 3200-3206, 2009.

[32] I. Osunkwo, T. R. Ziegler, J. Alvarez et al., "High dose vitamin D therapy for chronic pain in children and adolescents with sickle cell disease: results of a randomized double blind pilot study," British Journal of Haematology, vol. 159, no. 2, pp. 211-215, 2012.

[33] J. Han, X. Zhang, S. L. Saraf et al., "Risk factors for vitamin D deficiency in sickle cell disease," British Journal of Haematology, vol. 181, no. 6, pp. 828-835, 2018.

[34] T. C. Jackson, M. J. Krauss, M. R. Debaun, R. C. Strunk, and A. M. Arbeláez, "Vitamin D deficiency and comorbidities in children with sickle cell anemia," Pediatric Hematology and Oncology, vol. 29, no. 3, pp. 261-266, 2012.

[35] S. Chen, G. P. Sims, X. C. Xiao, Y. G. Yue, and P. E. Lipsky, "Modulatory effects of 1,25-dihydroxyvitamin $\mathrm{D}_{3}$ on human $\mathrm{B}$ cell differentiation," The Journal of Immunology, vol. 179, no. 3, pp. 1634-1647, 2007.

[36] S. Romagnani, "Regulation of the T cell response," Clinical \& Experimental Allergy, vol. 36, no. 11, pp. 1357-1366, 2006.
[37] J. R. Sabetta, P. DePetrillo, R. J. Cipriani, J. Smardin, L. A. Burns, and M. L. Landry, "Serum 25-hydroxyvitamin D and the incidence of acute viral respiratory tract infections in healthy adults," PLoS ONE, vol. 5, no. 6, Article ID e11088, 2010.

[38] S. A. Quraishi, E. A. Bittner, K. B. Christopher, C. A. Camargo, and J. Salluh, "Vitamin D Status and Community-Acquired Pneumonia: Results from the Third National Health and Nutrition Examination Survey," PLoS ONE, vol. 8, no. 11, p. e81120, 2013.

[39] A. A. Ginde, J. M. Mansbach, and C. A. Camargo, "Vitamin D, respiratory infections, and asthma," Current Allergy and Asthma Reports, vol. 9, no. 1, pp. 81-87, 2009.

[40] M. Urashima, T. Segawa, M. Okazaki, M. Kurihara, Y. Wada, and H. Ida, "Randomized trial of vitamin D supplementation to prevent seasonal influenza A in schoolchildren," American Journal of Clinical Nutrition, vol. 91, no. 5, pp. 1255-1260, 2010.

[41] M. T. Lee, M. Kattan, I. Fennoy et al., "Randomized phase 2 trial of monthly vitamin D to prevent respiratory complications in children with sickle cell disease," Blood Advances, vol. 2, no. 9, pp. 969-978, 2018. 


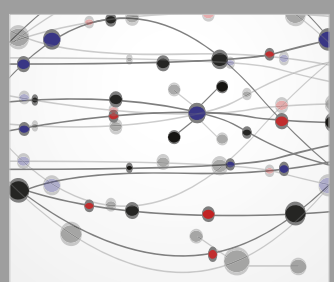

The Scientific World Journal
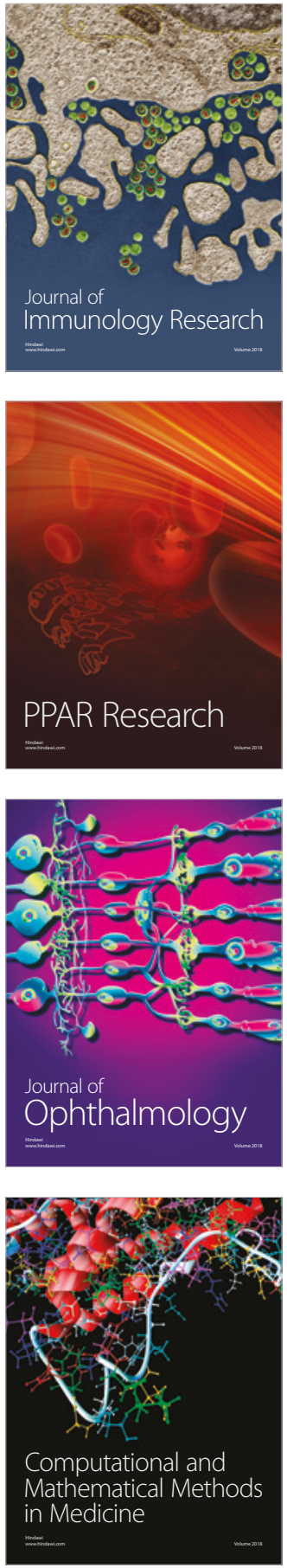

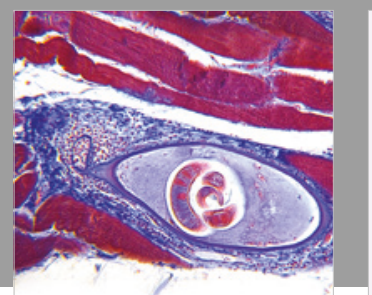

Gastroenterology Research and Practice

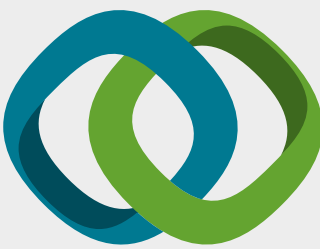

\section{Hindawi}

Submit your manuscripts at

www.hindawi.com
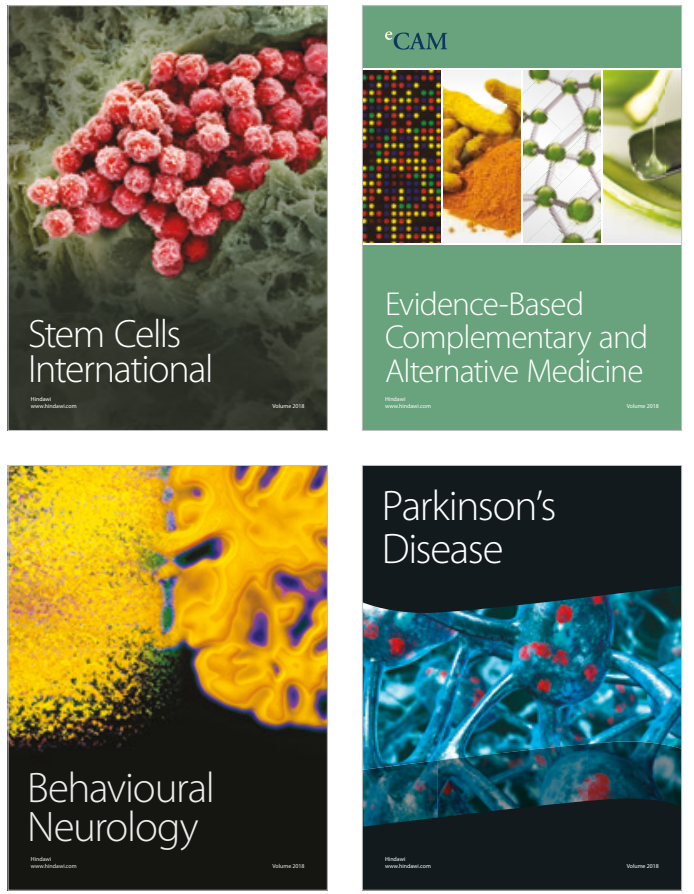

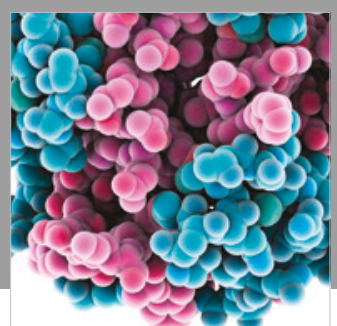

ournal of

Diabetes Research

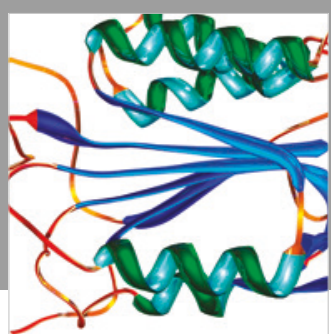

Disease Markers
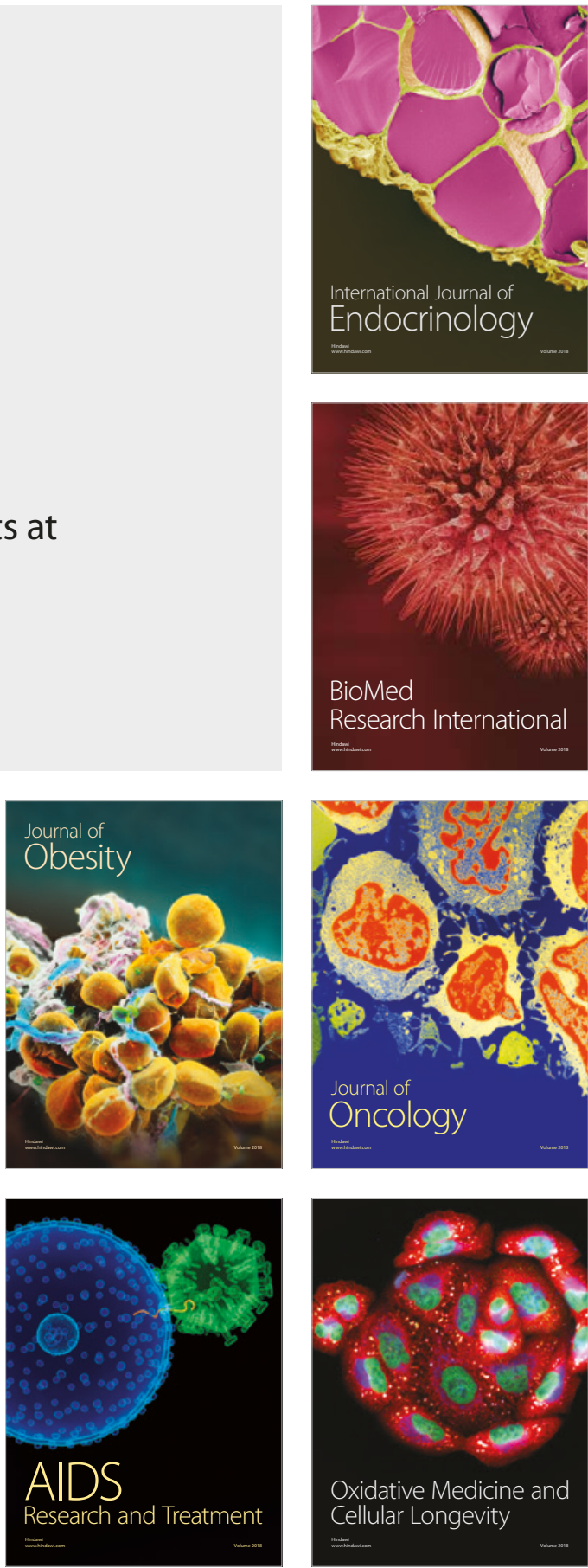